\section{Assessment of subclinical atherosclerosis in ankylosing spondylitis: correlations with disease activity indices}

\author{
F.M. Perrotta ${ }^{1}$, A. Scarno ${ }^{1}$, A. Carboni' ${ }^{1}$, V. Bernardo', \\ M. Montepaone ${ }^{1}$, E. Lubrano ${ }^{2}$, A. Spadaro ${ }^{1}$ \\ 'U.O.C. di Reumatologia, Dipartimento di Medicina Interna e Specialità Mediche, \\ Università "La Sapienza", Roma; \\ ${ }^{2}$ Dipartimento di Medicina e di Scienze per la Salute, Università del Molise, Campobasso, Italy
}

\title{
SUMMARY
}

The aim of the study was to evaluate atherosclerosis in ankylosing spondylitis (AS) through the assessment of morphological and functional measures of subclinical atherosclerosis.

Twenty patients $[M / F=12 / 8$, age (median/range) 43.5/28-69 years; disease duration (median/range) 9.7/1-36) years] with AS classified according to modified New York criteria and twenty age and sex related healthy controls with negative past medical history for cardiovascular events were enrolled in the study. In all patients and controls, the intima-media thickness (IMT) of common carotid artery, carotid bulb and internal carotid artery, and the flow-mediated dilatation (FMD) of non-dominant arm brachial artery were determined, using a sonographic probe Esaote GPX (Genoa, Italy). Furthermore, we assess the main disease activity and disability indices [bath ankylosing spondylitis disease activity index, ankylosing spondylitis disease activity score-eritrosedimentation rate (ASDAS-ESR), ASDAS-C-reactive protein (CRP), bath ankylosing spondylitis metrology index, bath ankylosing spondylitis functional index) and acute phase reactants. Plasmatic values of total cholesterol, low-density lipoprotein, high-density lipoprotein, triglyceride and homocysteine were carried out in all twenty patients.

IMT at carotid bulb was significant higher in patients than in controls $(0.67 \mathrm{~mm}$ vs $0.54 \mathrm{~mm} ; \mathrm{P}=0.03)$. FMD did not statistically differ between patients and controls ( $12.5 \%$ vs $15 \%$; P $>0.05)$. We found a correlation between IMT at carotid bulb and ESR (rho 0.43; P=0.04). No correlation was found between FMD and disease activity and disability indices.

This study showed that in AS patients, without risk factors for cardiovascular disease, carotid bulb IMT, morphological index of subclinical atherosclerosis, is higher than in controls.

Key words: Ankylosing spondylitis, Atherosclerosis, Intima-media thickness, Flow-mediated dilatation.

Reumatismo, 2013; 65 (3): 105-112

\section{INTRODUCTION}

A nkylosing spondylitis (AS) is a chronic systemic inflammatory disease that predominantly affects axial skeleton, with a possible peripheral and extra-articular involvement. AS patients have an increased mortality in respect to the general population (1), due to approximately $40 \%$ of cardiovascular disease cases, representing the leading cause of death (2). Several studies demonstrated the presence of an accelerated atherosclerotic process and increased cardiovascular morbidity and mortality in patients with chronic rheumatic diseases (3-5). In fact, it has been estimated that the relative risk of developing atherosclerotic disease is 3 in rheumatoid arthritis (3), 4-8 in systemic lupus erythematosus (6) and 1.2-1.8 in AS (7) compared to the general population. The link between inflammation and atherosclerosis is supported by observational studies performed on a large series of patients. These studies showed a close correlation between serum levels of acute phase reactants, in particular Creactive protein (CRP), and an increased risk of acute myocardial infarction, stroke and peripheral vascular disease. Also, CRP in long-standing rheumatoid arthritis patients correlated with the presence of subclinical atherosclerosis. Likewise,
Corresponding author: Prof. Antonio Spadaro Dipartimento di Medicina Interna e Specialità Mediche U.O.C. di Reumatologia Università "La Sapienza" Azienda Policlinico Umberto Viale del Policlinico, 155 - 00161 Roma, Italy E-mail: a.spadaro.reuma@virgilio.it 
chronic inflammation determined by CRP levels over an extended follow-up was also found to be associated with the development of cardiovascular events and cardiovascular mortality in rheumatoid arthritis $(3,6,8-11)$. The expression of cytokines and pro-inflammatory mediators plays a crucial role in all phases of atherosclerotic process in patients with rheumatic diseases (12). The presence of subclinical atherosclerosis could be detected by non-invasive ultrasonographic tools, through the assessment of carotid intima-media thickness (IMT) (13-15) and flow-mediated dilatation (FMD) $(16,17)$. Both methods are closely related to endothelial damage and dysfunction, early markers of atherosclerosis $(18,19)$. Prospective and retrospective studies showed that the assessment of endothelial function and arterial wall morphology could be useful in identifying patients at high risk of atherosclerosis and to predict the risk of developing cardiovascular events (19-21). Recently, it has been demonstrated that patients with rheumatoid arthritis and psoriatic arthritis have an increased IMT of carotid wall and abnormalities of FMD (22-26). The prevalence of increased subclinical atherosclerosis has been studied in AS through the assessment of IMT and FMD, but the presence of positive or negative history for cardiovascular risk factors, cardiovascular events or concomitant medications, have led to ambiguous results (27-32). Furthermore, in the assessment of carotid IMT, it was not considered the evaluation of different arterial segments (common carotid artery, internal carotid artery and bulb), characterized by a different progression of atherosclerotic process $(33,34)$. Finally IMT and FMD were analyzed in the same patients only in few studies $(27,31)$ and the correlations of these indices of subclinical atherosclerosis with the disease activity or disability indices must be better defined.

The aim of the present study is to investigate segmental carotid IMT and brachial arterial FMD in AS patients without cardiovascular risk factors and their possible correlation with disease activity and disability indices.

\section{MATERIALS AND METHODS}

Twenty patients $(\mathrm{M} / \mathrm{F}=12 / 8)$ with AS, classified according to modified New York criteria (35), and 20 healthy controls were enrolled. Subject's written consent was obtained according to the declaration of Helsinki, and the design of the work has been approved by local ethical committee. Exclusion criteria were: clinical history of hypertension; angina pectoris; ischemic heart disease; cerebrovascular events; transient ischemic attack; peripheral arterial disease; dyslipidaemia; diabetes mellitus. All patients and controls currently are non-smokers. AS patients in treatment, past or present, with TNF $\alpha$ inhibitors were excluded. In all AS patients the evaluation of the bath ankylosing spondylitis disease activity index (BASDAI) (36), ankylosing spondylitis disease activity score (ASDAS) (37), bath ankylosing spondylitis metrology index (BASMI) (38), bath ankylosing spondylitis functional index (BASFI) (39), eritrosedimentation rate (ESR), CRP, total cholesterol, low density lipoprotein (LDL), high density lipoprotein (HDL), triglyceride and homocysteine were performed.

The presence of subclinical atherosclerosis was assessed analyzing carotid IMT and FMD of brachial artery by high-resolution B-mode ultrasound (US) examination using Esaote GPX (Genoa, Italy), equipped with linear probe $(7-10 \mathrm{MHz})$, by an operator who was blinded to all clinical information.

\section{Carotid intima-media thickness}

Scanning was performed on the patient's carotid arteries in the supine position with the neck extended. The probe was placed in the longitudinal plane at the anterolateral position of the right side of the neck then followed by the left side of the neck. The measurement of carotid artery IMT was obtained at three sites: $1 \mathrm{~cm}$ distally to carotid bulb in common carotid artery (CCA), at carotid bulb (BULB), and $1 \mathrm{~cm}$ proximally to carotid bulb in the internal carotid artery (ICA) (Fig. 1). IMT was measured in the anterior and posterior wall of artery. The mean thickness (IMTm) at each site was recorded at the three sections 


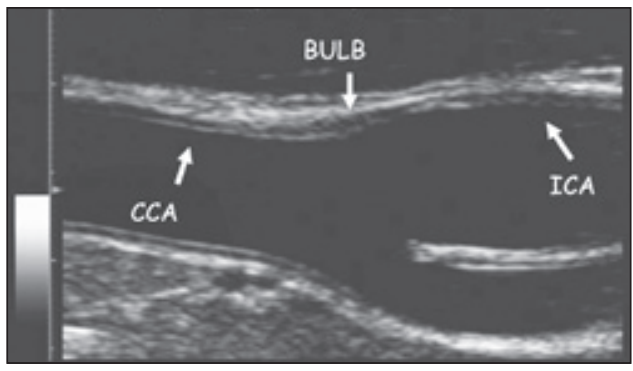

Figure 1 - Ultrasound imaging of right carotid artery and its segments: common carotid artery (CCA), carotid bulb (BULB), internal carotid artery (ICA).

bilaterally, after freezing the image on each occasion. IMT was defined as the distance between the inner echogenic line representing the intima-blood interface and the outer echogenic line representing the adventitia media junction. It was measured along the near and far wall of carotid artery. Furthermore, carotid bulb was defined as the point where the far wall deviated away from the parallel plane of the distal common carotid artery. Pathological IMT was defined as IMTm greater than $0.9 \mathrm{~mm}$ (40).

\section{Flow-mediated dilatation of brachial ar- tery}

Evaluation of FMD was obtained by longitudinal B-mode US scan of the brachial artery, approximately $5 \mathrm{~cm}$ above the elbow of the non-dominant arm. The evaluation of the arteriolar diameter was performed at baseline and after hyperemia induced by applying sphygmomanometer inflated to a pressure of about $50 \mathrm{mmHg}$ higher than the systolic blood pressure for $5 \mathrm{~min}$. The arteriolar diameter after induced hyperemia was obtained at 30s, 60s, 90s and 120s, synchronizing the measurements with the $\mathrm{R}$-wave electrocardiogram.

We calculated FMD as the maximum percentage increase (FMD\%) and as maximal difference $(\triangle \mathrm{FMD})$ of brachial artery diameter after induced hyperemia in comparison with baseline. All measurements were performed in a temperature controlled room, with the patient fasted for at least $12 \mathrm{~h}$. All medications, caffeine intake or smoke were discontinued at least 24 hours prior to the exam.

\section{Statistical analysis}

Categorical variables were analyzed by $\chi$-square test or Fisher's exact test. Continuous variables were analyzed by MannWhitney test for unpaired data or Wilcoxon test for paired data. The significance of correlations was determined using the Spearman's rank correlation coefficient. The results were presented as median $\left(25^{\text {th }}-75^{\text {th }}\right.$ percentile). $\mathrm{P}$ values less than 0.05 were considered significant.

\section{RESULTS}

Anthropometric, clinical and laboratory features of study population are shown in

Table I - Anthropometric, clinical and laboratory characteristics in ankylosing spondylitis patients $(\mathrm{n}=20)$.

\begin{tabular}{|c|c|}
\hline Male/female & $12 / 8$ \\
\hline Age (years) & $43.5(28-69)^{\star *}$ \\
\hline Disease duration (years) & $9.7(1-36)^{\star \star}$ \\
\hline ESR (mm/la h) & $14 / 4-35^{\star}$ \\
\hline $\operatorname{CRP}(\mathrm{mg} / \mathrm{dL})$ & $1.4 / 0.1-3.4^{*}$ \\
\hline Homocysteinemia (ng/dL) & $11.0 / 7.8-12.5^{*}$ \\
\hline Total cholesterol (mg/dL) & 175.0/153.5-207.5* \\
\hline $\mathrm{LDL}(\mathrm{mg} / \mathrm{dL})$ & $101.5 / 86.0-132.0^{*}$ \\
\hline $\mathrm{HDL}(\mathrm{mg} / \mathrm{dL})$ & $48.0 / 40.5-62.5^{*}$ \\
\hline Triglycerides $(\mathrm{mg} / \mathrm{dL})$ & $69 / 53-106^{*}$ \\
\hline BMI & $22.25 / 20.60-26.45^{\star}$ \\
\hline Mean blood pressure $(\mathrm{mmHg})$ & $103 / 97-113^{*}$ \\
\hline BASDAI & $4.22 / 2.36-6.01^{*}$ \\
\hline BASMI & $3 / 0.5-7.5^{*}$ \\
\hline BASFI & $4.75 / 2.18-8.30^{*}$ \\
\hline ASDAS-ESR & $3.15 / 1.375-4.025^{\star}$ \\
\hline ASDAS-CRP & $3.25 / 1.45-3.95^{\star}$ \\
\hline HLA-B27 + & $75 \%$ \\
\hline Extra-articular manifestation & $20 \%$ \\
\hline \begin{tabular}{|l|} 
NSAIDs \\
COXib \\
Analgesic \\
No treatment \\
\end{tabular} & \begin{tabular}{|l|}
$30 \%$ \\
$30 \%$ \\
$10 \%$ \\
$30 \%$ \\
\end{tabular} \\
\hline
\end{tabular}

ESR, eritrosedimentation rate; CRP, C-reactive protein; LDL, low-density lipoprotein; HDL, highdensity lipoprotein; BMI, body mass index; BASDAl, bath ankylosing spondylitis disease activity index; BASMI, bath ankylosing spondylitis metrology index; BASFI, bath ankylosing spondylitis functional index; ASDAS, ankylosing spondylitis disease activity score; NSAIDs, non steroidal antiinflammatory drugs; COXib, cyclooxygenase type 2. ${ }^{*}$ median $/ 25^{\text {th }}-75^{\text {th }}$ percentile; ${ }^{* *}$ median (range). 
Table II - Mean intima-media thickness and flow-mediated dilatation values (median/ $25^{\text {th }}-75^{\text {th }}$ percentile) in ankylosing spondylitis patients $(n=20)$ and healthy controls $(n=20)$

\begin{tabular}{|l|l|l|l|}
\hline & $\begin{array}{l}\text { AS } \\
(\mathbf{n}=20)\end{array}$ & $\begin{array}{l}\text { Controls } \\
(\mathbf{n}=20)\end{array}$ & P value \\
\hline CCA IMTm $(\mathrm{mm})$ & $0.6 / 0.523-0.700$ & $0.56 / 0.50-0.70$ & n.s. \\
\hline BULB IMTm $(\mathrm{mm})$ & $0.67 / 0.580-0.805$ & $0.54 / 0.49-0.6$ & 0.03 \\
\hline ICA IMTm $(\mathrm{mm})$ & $0.515 / 0.500-0.645$ & $0.53 / 0.500-0.66$ & n.s. \\
\hline$\triangle$ FMD $(\mathrm{mm})$ & $4.4 / 3.80-4.90$ & $4.60 / 3.70-5.90$ & n.s. \\
\hline FMD\% & $12.5 / 9.45-17.35$ & $15 / 12-22.25$ & n.s. \\
\hline
\end{tabular}

AS, ankylosing spondylitis; CCA, common carotid artery; IMTm, mean intima-media thickness; n.s., not significant; BULB, carotid bulb; ICA, internal carotid artery; FMD, flow-mediated dilatation.

Table I. All patients had serum total cholesterol, LDL, HDL, triglycerides and homocysteine levels within normal ranges. IMT

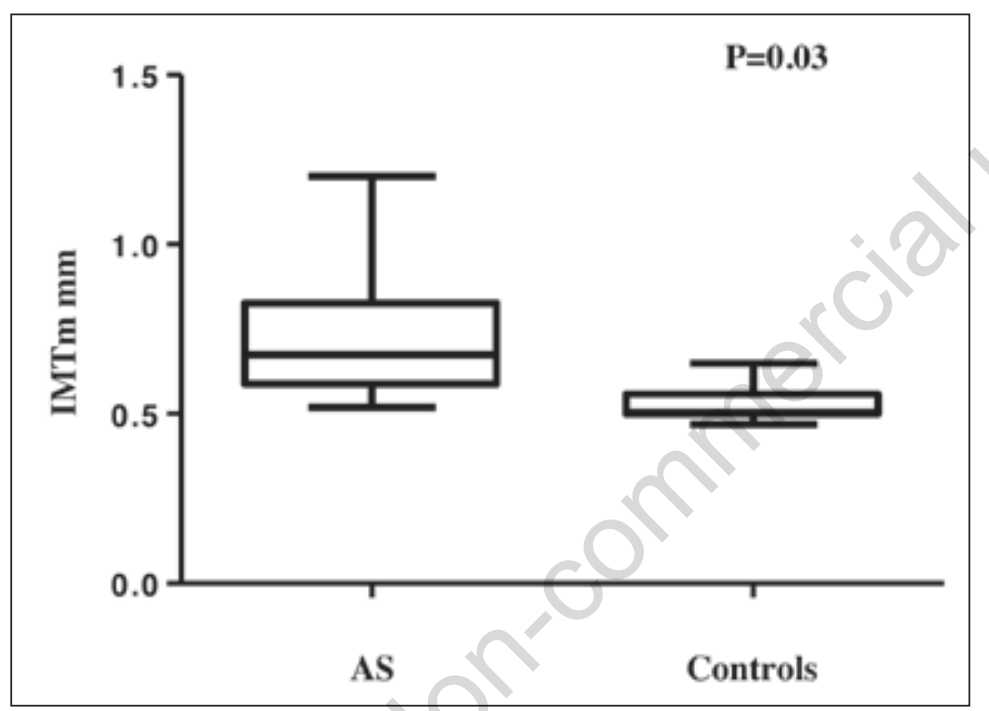

Figure 2 - Mean intima-media thickness (IMTm) values (box and whiskers plot: median $/ 25^{\text {th }}-75^{\text {th }}$ percentile/range) at carotid bulb in ankylosing spondylitis patients $(n=20)$ and controls $(n=20)(p=0.03)$. and FMD values (median $/ 25^{\text {th }}-75^{\text {th }}$ percentile) of AS patients and healthy controls are reported in Table II. IMT values at BULB were significantly higher in patients than in controls ( $\mathrm{P}=0.03$ ) (Fig. 2). No statistically difference was found in IMT values at CCA and ICA segments. No patients or controls had IMT values greater than $0.9 \mathrm{~mm}$. The assessment of FMD showed no significant differences between two groups. No correlation was found between IMT and FMD values (rho $=0.15$ ).

The correlations between clinical and laboratory indices and US markers of subclinical atherosclerosis are shown in Table III. In AS patients, the only significant correlation was found between BULB IMT with ESR values (rho $0.43 ; \mathrm{P}=0.04$ ). No statistically significant correlation was found between IMT and FMD values with disease duration. Finally, there were statistically significant inverse correlations between plasma HDL values with BASDAI (rho $-0.45 ; \mathrm{P}=0.046)$ and CRP levels $(-0.47$ : $\mathrm{P}=0.03)$.

Table III - Correlations (rho) between carotid intima-media thickness and brachial flow-mediated dilatation with disease activity and disability index in ankylosing spondylitis patients $(n=20)$.

\begin{tabular}{|l|l|l|l|l|l|}
\hline & CCA-IMT & BULB-IMT & ICA-IMT & FMD $\%$ & SFMD \\
\hline BASDAI & 0.152 & 0.270 & 0.189 & 0.115 & 0.184 \\
\hline BASMI & 0.352 & 0.201 & 0.156 & 0.206 & 0.069 \\
\hline BASFI & 0.362 & 0.300 & 0.074 & 0.066 & 0.020 \\
\hline ESR & 0.06 & $0.431^{*}$ & 0.272 & 0.052 & 0.439 \\
\hline CRP & 0.205 & 0.237 & 0.003 & 0.110 & 0.083 \\
\hline ASDAS (ESR) & 0.03 & 0.32 & 0.14 & 0.20 & 0.13 \\
\hline ASDAS (CRP) & 0.03 & 0.34 & 0.16 & 0.24 & 0.07 \\
\hline
\end{tabular}

CCA, common carotid artery; IMT, intima-media thickness; BULB, carotid bulb; ICA, internal carotid artery; FMD, flow-mediated dilatation; BASDAI, bath ankylosing spondylitis disease activity index; BASMI, bath ankylosing spondylitis metrology index; BASFI, bath ankylosing spondylitis functional index; ESR, eritrosedimentation rate; CRP, C-reactive protein; ASDAS, ankylosing spondylitis disease activity score. ${ }^{*} \mathrm{P}<0.05$. 


\section{DISCUSSION}

An increased mortality has been reported in AS patients compared to the general population (1), and in approximately $40 \%$ of cases, cardiovascular disease is the leading cause of death (2). In particular, standardized mortality ratio is 1.37 for ischemic heart disease, 1.25 for cerebrovascular diseases, 1.36 for other vascular diseases compared to the general population (2). Increased cardiovascular morbidity and mortality in patients with chronic rheumatic diseases and the presence of an accelerated atherosclerotic process, related to inflammatory process, have been widely demonstrated (3-5). Furthermore, IMT and FMD are closely related to endothelial damage and dysfunction, early indicators of atherosclerosis $(18,19)$. However, Mathieu et al. found no statistically significant differences in CCA or BULB IMT values in $60 \mathrm{AS}$ patients and age and sex-matched controls (29). It should be noted that in relation to risk factors that could modify IMT (41-43) in this study there were higher levels of plasma cholesterol and glucose in controls than in patients (29). Similar results have also been obtained in other studies (30, 31 ), which have not considered the bias of the presence of certain cardiovascular risk factors. However, when the criteria of exclusion included the presence of cardiovascular risk factors or cardiovascular events, it has been demonstrated an increased prevalence of subclinical atherosclerosis in AS $(27,28)$. In fact, Bodnar et al. demonstrated increase IMT values at CCA level and a reduction of FMD in 43 AS patients compared to controls (27). Similar results were obtained by Hamdi et al. in a study on 60 AS patients and controls with no history of risk factors or cardiovascular events. In this study CCA IMT values were significantly higher in patients with AS than in controls $(0.51 \mathrm{~mm}$ vs $0.39 \mathrm{~mm}, \mathrm{P}=0.001)$ (28). Gonzales Juanatey et al. also found increased IMT values and prevalence of atherosclerotic plaques in a cohort of 64 patients with AS with respect to controls. Moreover, the best predictor of carotid plaques in patients with AS was ESR at time of disease diagnosis (32). It has to be highlighted that these studies did not consider the evaluation of single carotid segments. This aspect is particularly important in relation to the evidence that the classic risk factors for atherosclerosis may have a different impact on the intima-media thickness in relation to anatomical sites (33). Moreover, the progression of IMT is not homogeneous in the different arterial segments, and could be greater at BULB and ICA level (34). In our study, the evidence of IMT values significantly increased in patients with AS compared to controls only at carotid bulb segment confirms that the evaluation of this district is essential in the study of subclinical atherosclerosis. In fact, in this anatomical site, changes in endothelial structure and turbulence due to carotid bifurcation may predispose to endothelial damage. With regards to the assessment of endothelial dysfunction by FMD, we have not found significant differences between patients and controls in the endotheliummediated response or correlation with disease activity and disability indices, according to other authors (31). However, Bodnar found a reduction of FMD in his cohort of AS patients (27). Changes in FMD assessment methods (for example the different time of occlusion) could explain the differences among these studies (44). The discrepancy in IMT and FMD findings among different studies could also be explained with the presence of concomitant medications such as non steroidal anti-inflammatory drugs (NSAIDs), selective inhibitors of cyclooxygenase type 2 (coxibs) and TNF $\alpha$ inhibitors commonly used in AS. In fact, NSAIDs and coxibs may be able to alter the vasodilator response endothelium mediated by production of vasoactive substances (45), while anti-TNF $\alpha$ drugs can induce significant changes in carotid atherosclerotic progression and improve endothelial function $(46,47)$. However, it should be noted that in our study AS patients were not treated with anti-TNF $\alpha$ drugs and discontinued NSAIDs or coxibs at least $24 \mathrm{~h}$ before the test. Moreover, inflammatory burden in AS patients is often less severe than in psoriatic arthritis or rheumatoid ar- 
thritis patients (48). This may explain, at least in part, why endothelial dysfunction was observed in patients with psoriatic arthritis and not in this smaller cohort of AS patients.

In our study we also found a correlation between carotid bulb IMT and ESR values, suggesting that inflammation in AS may accelerate atherosclerotic process. It was also highlighted an inverse correlation between BASDAI and CRP with plasma concentrations of HDL in support of the hypothesis that the disease activity may influence lipid balance in pro-atherogenic profile, also in patients with AS, as observed in rheumatoid arthritis (49).

In conclusion, our results showed that, in the absence of cardiovascular risk factors, there is an alteration of carotid wall morphology at bulb segment in AS patients, probably due to the presence of a chronic inflammatory process, typical of AS. These results suggest that, in the study of subclinical atherosclerosis, morphological evaluation of the carotid wall should be performed in all arterial segments (CCA, BULB and ICA). We need further longitudinal studies of larger series of patients with AS to define the predictive value of endothelial dysfunction to development of cardiovascular events.

\section{REFERENCES}

1. Bakland G, Gran JT, Nossent JC. Increased mortality in ankylosing spondylitis is related to disease activity. Ann Rheum Dis. 2011; 70: 1921-5.

2. Szabo SM, Levy AR, Rao SR, et al. Increased risk of cardiovascular and cerebrovascular diseases in individuals with ankylosing spondylitis: a population-based study. Arthritis Rheum 2011; 63: 3294-304.

3. Del Rincón I, Williams K, Stern MP, et al. Association between carotid atherosclerosis and markers of inflammation in rheumatoid arthritis patients and healthy subjects. Arthritis Rheum. 2003; 48: 1833-40.

4. Toledano E, Candelas G, Rosales Z, et al. A meta-analysis of mortality in rheumatic diseases. Reumatol Clin. 2012; 8: 334-41.

5. Libby P. Role of inflammation in atherosclerosis associated with rheumatoid arthritis. Am J Med. 2008; 121: 21-31.
6. Sherer Y, Shoenfeld Y. Mechanisms of disease: atherosclerosis in autoimmune diseases. Nat Clin Pract Rhematol. 2006; 2: 99-106.

7. Nurmohamed MT, van der Horst-Bruinsma I, Maksymowych WP. Cardiovascular and cerebrovascular diseases in ankylosing spondylitis: current insights. Curr Rheumatol Rep. 2012; 14: 415-21.

8. Auer J, Berent R, Lassnig E, Eber B. C-reactive protein and coronary artery disease. Jpn Heart J. 2002; 43: 607-19.

9. Krintus M, Kozinski M, Stefanska A, et al. Value of C-reactive protein as a risk factor for acute coronary syndrome: a comparison with apolipoprotein concentrations and lipid profile. Mediators Inflamm. 2012; 2012: 419804.

10. Gonzalez-Gay MA, Gonzalez-Juanatey C, Piñeiro A, et al. High-grade C-reactive protein elevation correlates with accelerated atherogenesis in patients with rheumatoid arthritis. J Rheumatol. 2005; 32: 1219-23.

11. Gonzalez-Gay MA, Gonzalez-Juanatey C, Lopez-Diaz MJ, et al. HLA-DRB1 and persistent chronic inflammation contribute to cardiovascular events and cardiovascular mortality in patients with rheumatoid arthritis. Arthritis Rheum. 2007; 57: 125-32.

12. Ross R. Atherosclerosis-an inflammatory disease. N Engl J Med. 1999; 340: 115-26.

13. Baldassarre D, Amato M, Bondioli A, et al. Carotid artery intima-media thickness measured by ultrasonography in normal clinical practice correlates well with atherosclerosis risk factors. Stroke. 2000; 31: 2426-30.

14. Simon A, Gariepy J, Chironi G, et al. Intimamedia thickness: a new tool for diagnosis and treatment of cardiovascular risk. J Hypertens. 2002; 20: 159-69.

15. Phan TG, Beare RJ, Jolley D, et al. Carotid artery anatomy and geometry as risk factors for carotid atherosclerotic disease. Stroke. 2012; 43: 1596-601

16. Faulx MD, Wright AT, Hoit BD. Detection of endothelial dysfunction with brachial artery ultrasound scanning. Am Heart J. 2003; 145: 943-51.

17. Corretti MC, Anderson TJ, Benjamin EJ, et al. International Brachial Artery Reactivity Task Force. Guidelines for the ultrasound assessment of endothelial-dependent flow-mediated vasodilation of the brachial artery: a report of the International Brachial Artery Reactivity Task Force. J Am Coll Cardiol. 2002; 39: 25765.

18. Shechter M, Issachar A, Marai I, et al. Longterm association of brachial artery flow-mediated vasodilation and cardiovascular events in middle-aged subjects with no apparent heart disease. Int J Cardiol. 2009; 134: 52-8.

19. Staub D, Meyerhans A, Bundi B, et al. Prediction of cardiovascular morbidity and mortality: comparison of the internal carotid artery 
resistive index with the common carotid artery intima-media thickness. Stroke. 2006; 37: 800-5.

20. Sitzer M, Puac D, Buehler A, et al. Internal carotid artery angle of origin: a novel risk factor for early carotid atherosclerosis. Stroke. 2003; 34: 950-5.

21. Simon A, Megnien JL, Chironi G. The value of carotid intima-media thickness for predicting cardiovascular risk. Arterioscler Thromb Vasc Biol. 2010; 30: 182-5.

22. Gonzalez-Juanatey C, Llorca J, Amigo-Diaz E, et al. High prevalence of subclinical atherosclerosis in psoriatic arthritis patients without clinically evident cardiovascular disease or classic atherosclerosis risk factor. Arthritis Rheum. 2007; 57: 1074-80.

23. Contessa C, Ramonda R, Lo Nigro A, et al. Subclinical atherosclerosis in patients with psoriatic arthritis: a case-control study. Reumatismo. 2009; 61: 298-305.

24. Södergren A, Karp K, Boman K, et al. Atherosclerosis in early rheumatoid arthritis: very early endothelial activation and rapid progression of intima media thickness. Arthritis Res Ther. 2010; 12: 158.

25. Profumo E, Di Franco M, Buttari B, et al. Biomarkers of subclinical atherosclerosis in patients with autoimmune disorders. Mediators Inflamm. 2012; 2012: 503942.

26. Fan CY, Zhang ZY, Mei YF, et al. Impaired brachial artery flow-mediated dilation and increased carotid intima-media thickness in rheumatoid arthritis patients. Chin Med J (Engl). 2012; 125: 832-7.

27. Bodnár N, Kerekes G, Seres I, et al. Assessment of subclinical vascular disease associated with ankylosing spondylitis. J Rheumatol. 2011; 38: 723-9.

28. Hamdi W, Chelli Bouaziz M, Zouch I, et al. Assessment of preclinical atherosclerosis in patients with ankylosing spondylitis. J Rheumatol. 2012; 39: 322-6.

29. Mathieu S, Joly H, Baron G, et al. Trend towards increased arterial stiffness or intimamedia thickness in ankylosing spondylitis patients without clinically evident cardiovascular disease. Rheumatology (Oxford). 2008; 47: 1203-7.

30. Choe JY, Lee MY, Rheem I, et al. No differences of carotid intima-media thickness between young patients with ankylosing spondylitis and healthy controls. Joint Bone Spine. 2008; 75: 548-53.

31. Erre GL, Sanna P, Zinellu A, et al. Plasma asymmetric dimethylarginine (ADMA) levels and atherosclerotic disease in ankylosing spondylitis: a cross-sectional study. Clin Rheumatol. 2011; 30: 21-7.

32. Gonzalez-Juanatey C, Vazquez-Rodriguez TR, Miranda-Filloy JA, et al. The high prevalence of subclinical atherosclerosis in patients with ankylosing spondylitis without clinically evident cardiovascular disease. Medicine (Baltimore). 2009; 88: 358-65.

33. Dietrich M, Jacques PF, Polak JF, et al. Segment-specific association between plasma homocysteine level and carotid artery intimamedia thickness in the Framingham Offspring Study. J Stroke Cerebrovasc Dis. 2011; 20: 155-61.

34. Espeland MA, Tang R, Terry JG, et al. Associations of risk factors with segment-specific intimal-medial thickness of the extracranial carotid artery. Stroke. 1999; 30: 1047-55.

35. Van der Linden S, Valkenburg HA, Cats A. Evaluation of diagnostic criteria for Ankylosing Spondylitis. A proposal for modification of the New York criteria. Arthritis Rheum. 1984; 27: 361-8.

36. Garret S, Jenkinson T, Whitelock H, et al. A new approach to defining disease status in ankylosing spondylitis: the Bath Ankylosing spondylitis Activity Index. J Rheumatol. 1994; 21: 2286-91.

37. Machado P, Landewé R, Lie E, et al. Assessment of SpondyloArthritis international Society. Ankylosing Spondylitis Disease Activity Score (ASDAS): defining cut-off values for disease activity states and improvement scores. Ann Rheum Dis. 2011; 70: 47-53.

38. Jenkinson TR, Mallorie PA, Whitelock HC, et al. Defining spinal mobility in ankylosing spondylitis (AS). The Bath AS Metrology Index. J Rheumatol. 1994; 21: 1694-8.

39. Calin A, Garrett S, Whitelock H, et al. A new approach to defining functional ability in ankylosing spondylitis: the development of the Bath Ankylosing Spondylitis Functional Index. J Rheumatol. 1994; 21: 2281-5.

40. Mancia G, De Backer G, Dominiczak A, et al. Guidelines for the management of arterial hypertension: the task force for the management of arterial hypertension of the European Society of Hypertension (ESH) and of th European Society of Cardiology (ESC). Eur Heart J. 2007; 28: 1462-536.

41. Poli A, Tremoli E, Colombo A, et al. Ultrasonographic measurement of the common carotid artery wall thickness in hypercholesterolemic patients. A new model for the quantitation and follow-up of preclinical atherosclerosis in living human subjects. Atherosclerosis. 1988; 70: 253-61.

42. Päivänsalo M, Rantala A, Kauma $H$, et al. Prevalence of carotid atherosclerosis in middle-aged hypertensive and control subjects. A cross-sectional systematic study with duplex ultrasound. J Hypertens. 1996; 14: 1433-9.

43. Vigili de Kreutzenberg S, Tiengo A, Avogaro A. Cerebrovascular disease in diabetes mellitus: the role of carotid intima-media thickness. Nutr Metab Cardiovasc Dis. 2009; 19: 667-73. 44. Bots ML, Westerink J, Rabelink TJ, de Koning 
EJ. Assessment of flow-mediated vasodilatation (FMD) of the brachial artery: effects of technical aspects of the FMD measurement on the FMD response. Eur Heart J. 2005; 26: 363-8.

45. Flórez A, de Haro J, Martínez E, et al. Selectivecyclooxygenase- 2 inhibition reduces endothelial dysfunction and improves inflammatory status in patients with intermittent claudication. Rev Esp Cardiol. 2009; 62: 851-7.

46. Gonzalez-Juanatey C, Vazquez-Rodriguez TR, Miranda-Filloy JA, et al. Anti-TNF-alphaadalimumab therapy is associated with persistent improvement of endothelial function without progression of carotid intima-media wall thickness in patients with rheumatoid ar- thritis refractory to conventional therapy. Mediators Inflamm. 2012; 2012: 674265.

47. Mazzoccoli G, Notarsanto I, De Pinto GD, et al. Anti-tumor necrosis factor- $\alpha$ therapy and changes of flow-mediated vasodilatation in psoriatic and rheumatoid arthritis patients. Intern Emerg Med. 2010; 5: 495-500.

48. Gonzalez-Juanatey C, Llorca J, Miranda-Filloy JA, et al. Endothelialdysfunction in psoriatic arthritis patients without clinically evident cardiovascular disease or classic atherosclerosis risk factors. Arthritis Rheum. 2007; 57: 287-93.

49. Lee YH, Choi SJ, Ji JD, et al. Lipoprotein(a) and lipids in relation to inflammation in rheumatoid arthritis. Clin Rheumatol. 2000; 19: 324-5. 